Conf-911109--1

$\mathrm{ANL} / \mathrm{CP}--73319$

DE 92001924

\title{
AEM ANALYSES OF SRL 131 GLASS ALTERED AS A FUNCTION OF SA/ ${ }^{*}$
}

James J. Mazer, John K. Bates,

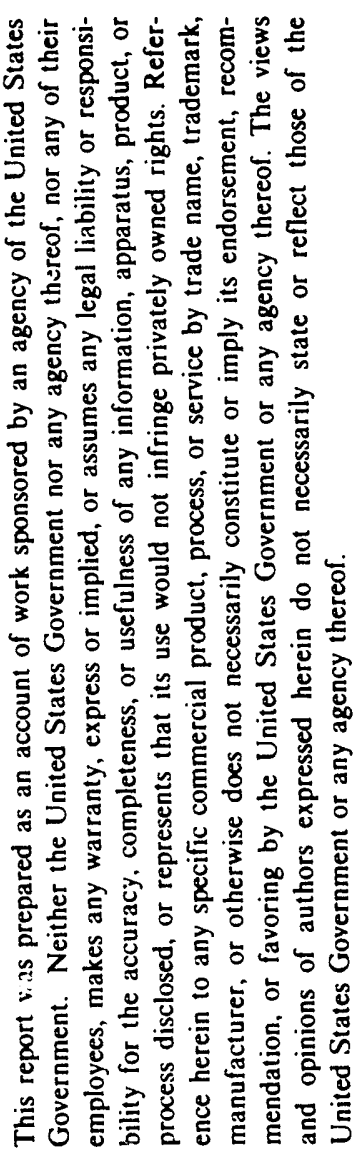

Bruce M. Biwer, and Charles R. Bradley

Chemical Technology Division

Argonne National Laboratory

Argonne, IL 60439

\begin{abstract}
The submitted manuscript has been authored
by a contractor of the U.S. Government

under contract No. W.31.109ENG-38.

Accordingly, the U.S. Government retains a

nonexclusive, royalty-free licerise to publish

or reproduce the published form of this

contribution, or allow others to do so, for

U.S. Government purposes.
\end{abstract}

Submitted to

Fall 1991 Materials Research Society Meeting Scientific Basis for Nuclear Waste Management XV

Strasbourg, France

November 4-7, 1991

"Work supported by the U.S. Department of Energy, Office of Environmental Restoration and Waste Management, under Contract W-31-109-ENG-38. 
JAMES J. MAZER, JOHN K. BATES, BRUCE M. BIWER, AND C. R. BRADLEY Chemical Technology Division, Argonne National Laboratory, Argonne, IL 60439

\section{INTRODUCTION}

Experimental studies of silicate glass/water reactions at low temperatures have previously identified the glass surface area-to-solution volume ratio (SA/V) as a significant rate determining parameter [1-4]. The value produced when SA/V is multiplied by reaction time, hereafter referred to as SVT, has been proposed as a scaling factor for comparing experimental results collected under different test conditions and for extrapolating short-term results to longer periods of time. Developing an understanding of the effect of SAN is needed for modeling experimental results where SAN ranges in value or may vary during experiments. It is also useful to understand the effect of SA/V for modeling natural systems where this value almost certainly varies, such as during the hyorothermal diagenesis of natural glasses or projecting the long-term reaction of water and borosilicate nuclear waste glass in a geologic repository.

Recent studies have concluded that glass/water reaction mechanisms consist of simultaneous, competing processes, including ion exchange, molecular water diffusion, detachment of silica units from the glass surface (etching) and secondary mineral formation [5-7]. The relative importance of each reaction process is thought to be dependent on the total effect of other experimental parameters such as reaction temperature, SAN, reaction time, solution composition and the initial glass composition.

SAN relationships are often represented by a form of the equation:

$$
\frac{d C_{i}}{d t}=k \frac{S A}{V}\left(C_{s a t}-C_{i}\right)^{n}
$$

where $C_{i}$ refers to the concentration of species $i_{i} t$ is time, SA is the glass suiface area, $V$ is volume, and $C_{\text {sat }}$ i refers to the saturation concentration of species with respect to secondary alteration phases, a value dependent on the overall solution composition and temperature $[8,9]$. The constant $k$ includes the temperature dependency of the reaction and the constant $n$ is an empirical factor related to the order of the reaction. Thus, the reaction mechanism is not assumed to be a function of SA/V. It has been observed that static leach-type experiments conducted at relatively large SA/V ratios ( hundreds $\mathrm{m}^{-1}$ ) approach saturation or near saturation with respect to secondary phases relatively sooner $[3,4,10]$ and form thinner alteration layers $[1,4,11]$ than samples identically reacted at smaller SAN.

If saturation of the reacting solution with respect to secondary phase formation slows the overall rate of reaction, then by increasing the SA/V ratio the approach to saturation can be reached in a shorter period of time (i.e., $\mathrm{C}_{\mathrm{i}}$ becomes larger sooner). At larger SA/V, more glass comes into contact with the leachant, therefore, more species are released to solution per unit time. The correlation of thinner alteration layers with larger SAN reflects the fact that less glass surface area (although an identical volume) need undergo reaction to achieve solution saturation, relative to experiments with smaller SANV ratios. This has 
formed the basis for using SA/V to accelerate the reaction progress of hydrothermal tests of nuclear waste glasses.

While SVT scaling shows some correlations far from saturation, its application to near saturation conditions has been questioned $[10,12]$ and the effects of reacted layer development and secondary phase formation have been neglected. Previously, Pederson et al. found that the relative elemental concentrations, as measured with SIMS depth profiling, within the alteration layers formed on PNL 76-68 glass contained similar structures, although on different depth scales. The solution results, scaled for SVT, were equivalent.

The goal of the present study was to consider the effects of SVT scaling on glass/water reactions, particularly with respect to characterizing the alteration layer formed at different values of SVT. Preliminary testing indicated that a $\mathrm{Na}$ rich borosilicate glass, SRL 131, would achieve significant reaction in a relatively short period of time. While 131 glass is not expected to be produced at the DWPF its composition falls in the range for consideration. The results presented here include a comparison of the solution concentrations and detailed descriptions of the alteration layers that formed, analyzed using Analytical Electron Microscopy $(A E M)$. The examination of solution concentrations and solids changes simultaneously allows a more complete assessment of the effects of SAN on glass reaction.

\section{EXPERIMENTAL}

SRL 131 glass, a complex borosilicate glass, was synthesized by melting the base frit in a Pt crucible at $1150^{\circ} \mathrm{C}$ for 15 minutes. This melt was then poured into a $\mathrm{Pt} / 5 \%$ Au mold and subsequently annealed at $500^{\circ} \mathrm{C}$ for two hours after which the furnace was turned off and allowed to cool to room temperature. Chemical analyses of the glass composition were made, using a combination of acid dissolution/ICP techriques. Monolithic glass samples, in the form of discs $110 \mathrm{~mm}$ diameter; $1 \mathrm{~mm}$ thick), were prepared using a low speed diamond wafering saw and water as a lubricant. Other than cleaning the discs by multiple rinsing in distilled water and absolute ethanol, the glass surfaces were reacted with an "as cut" (approximately 600 grit) finish. The surface area of each disc was estimated geometrically and is approximately $1.7 \pm 0.05 \mathrm{~cm}^{2}$. Powdered glasses with size fraction 100 to 200 mesh were also used.

Hydrothermal leaching experiments were conducted at $90^{\circ} \mathrm{C}$ in Teflon ${ }^{\circledR}$ vessels in static leach tests using a modified MCC-1 testing procedure consistent with previous studies $[5,13]$. Distilled deionized water was used as the reaction leachant in all experiments. After each experiment was terminated, the monoliths were allowed to air-dry, then stored in a dry, dust-free container until preparation for analysis. The reaction solution was collected and aliquots of the leachants were analyzed for cation concentrations by ICP ( $\mathrm{Si}, \mathrm{Al}, \mathrm{Na}, \mathrm{Ca}, \mathrm{Mg}, \mathrm{Mn}, \mathrm{Fe}, \mathrm{Ni}, \mathrm{Li}$ and $\mathrm{B}$ ) and room temperature $\mathrm{pH}$, using a standard $\mathrm{pH}$ meter $( \pm 0.05 \mathrm{pH}$ units).

The study consisted of three experiments performed where SVT equalled $1000 \mathrm{~d} / \mathrm{m}$ [sample $A$ (SA $/ \mathrm{V}=10 \mathrm{~m}^{-1}, 100$ days); sample $B\left(S A N=50 \mathrm{~m}^{-1}\right.$, 20 days) and sample $C$ (SA/V $=100 \mathrm{~m}^{-1}, 10$ days)] and $2500 \mathrm{~d} / \mathrm{m}$ [sample $D$ $\left(\mathrm{SA} / \mathrm{V}=1000 \mathrm{~m}^{-1}, 2.5\right.$ days $)$ and sample $E\left(S A / \mathrm{V}=2000 \mathrm{~m}^{-1}, 1.25\right.$ days)]. Preliminary examination of the altered glass surfaces was performed with both optical and scanning electron microscopy (SEM). In addition to the glass surface, cross-sections of each sample were prepared for SEM analyses of the layer 
- thickness and structure. These analyses allowed a large number of areas of the sample to be examined, though in relatively coarse detail. More detailed analyses of typical alteration features were performed using analytical electron microscopy (AEM).

Thin sections for AEM analyses were prepared using an ultramicrotome equipped with a diamond knife and procedures that allowed preparation of micrometer-sized specimens [14]. Samples prepared in this fashion have previously been shown to permit direct high-resolution observation of intact alteration assemblages produced during glass/water interactions [5]. A JEOL 2000FXII transmission electron microscope was used to examine electron transparent sections (500-800 $\AA$ thick) using lattice-fringe imaging, selected area diffraction (SAD), microdiffraction, and semi-quantitative thin-film $X$-ray analysis $[15,16]$. The $X$-ray analyses were performed using techniques similar to those reported by Abrajano et al. 1990, and are believed to be on the order of $\pm 10 \%$ relative error for major elements and $\pm 30 \%$ for minor elements.

\section{RESULTS AND DISCUSSION}

The glass surface areas, solution volumes, SA/N ratios and experimental times used in these experiments are representative of those typically used in hydrothermal leaching experiments and, therefore, will allow us to consider SAN effects in relation to solution concentrations and alteration phase formation. Since the SVT value for each set of samples is either 1000 or $2500 \mathrm{~d} / \mathrm{m}$, the SVT scaling approach would predict that identical reaction, (and, therefore, features and solution concentrations) should be observed within each sample set.

\section{Solution Analyses}

The final solution concentrations of the major elements in the glass for each experiment are presented in Table I. A comparison of the values suggests that, except for $\mathrm{Mn}$, a minor element in the glass, the differences in each case are greater than expected from experimental error, approximately $\pm 10 \%$.

Measurements of the release of $\mathrm{Li}, \mathrm{B}$ and $\mathrm{Na}$ and $\mathrm{pH}$, species thought to be soluble under hydrothermal conditions, diverge slightly. Solution concentrations for samples reacted at SVT of $1000 \mathrm{~d} / \mathrm{m}$ are significantly different, with respect to $\mathrm{Mn}, \mathrm{Fe}, \mathrm{Mg}$, and Al. Solution concentrations for samples reacted at SVT of $2500 \mathrm{~d} / \mathrm{m}$ are even more divergent from each other and concentrations of $\mathrm{Na}, \mathrm{Si}$, and $\mathrm{Mn}$ differ significantly.

\section{Glass Surface Analyses}

Noticeable differences in the appearance of the reacted glass surfaces were evident for samples $A, B$, and $C$ (SVT $=1000 \mathrm{~d} / \mathrm{m}$ ) using light and SEM microscopy. Sample $A$ has a honeycombed-type texture with what appear to be interlocking laths, typical of smectite clays [17]. A number of micron sized particles were also observed within the alteration layer. Although we were unable to ascertain their identity using this technique, energy dispersive spectrometry (EDS) analysis indicates that they are rich in manganese. Samples $B$ and $C$ are grossly similar in 
Table I

Solution Concentrations (mg/L) of Samples A (10 m-1, 100 days),

$B\left(50 \mathrm{~m}^{-1}, 20\right.$ days), $\mathrm{C}\left(100 \mathrm{~m}^{-1}, 10\right.$ days $)$,

$D\left(1000 \mathrm{~m}^{-1}, 2.5\right.$ days $), E\left(2000 \mathrm{~m}^{-1}, 1.25\right.$ days $)$.

\begin{tabular}{|c|c|c|c|c|c|c|c|c|c|c|c|c|}
\hline & & $\mathrm{pH}$ & ن & $B$ & $\mathrm{Ja}$ & $\mathrm{Mg}$ & Al & Si & $\mathrm{Ca}$ & $\mathrm{Mn}$ & $\mathrm{Fe}$ & $\mathrm{Ni}$ \\
\hline A & 1000 & 039 & & 24.30 & 72.8 & 0.04 & 0.64 & 87.2 & $<0.01$ & 0.23 & $0 \quad 02$ & 0.04 \\
\hline $\bar{B}$ & 1000 & & 15.44 & 24.85 & 74.0 & 0.28 & 2.40 & 88.1 & $<0.03$ & 0.33 & .25 & 60.08 \\
\hline C & 000 & 83 & 16.94 & 27.66 & 85.4 & 0.24 & 2.95 & 97.2 & $<0.03$ & 0.32 & 0.37 & $=0.08$ \\
\hline & & 0 & 8.05 & 86.33 & 241 & .48 & 2.06 & 195 & $<0.03$ & 0.92 & 2.30 & 0.18 \\
\hline & 2500 & 10.9 & 42.95 & 75.74 & 214 & 0.28 & 2.49 & 175 & 0.02 & 0.55 & 2.15 & 0.18 \\
\hline
\end{tabular}

appearance to sample $A$, but close examination indicates that their surfaces are made up of somewhat coarser interlocking particles. Thorough examination of these surfaces was unable to detect any Mn-rich phases. The surfaces of samples $D$ and $E(S V T=2500 \mathrm{~d} / \mathrm{m}$ ) were similar in appearance to samples $A, B$ and $C$, although the relatively coarse interlocking laths did not contain any $\mathrm{Mn}$-rich phases.

\section{Reaction Layer Analyses}

Analyses and characterizations of the layer formed during interactions with water were carried out using multiple analytical techniques. The following summarizes our description of the reaction layer formed on each sample. The nature of each reaction layer was such that we were able to identify constituent sub-layers. These layers were analogous to those previously identified on this type of altered glass $[5,13]$. The phase identifications reported below are based on a combination of SAD, microdiffraction, lattice imaging, and energy dispersive spectrometry (EDS).

\section{Sample A}

The alteration layer formed on sample A consists of a total of six sub-layers with an overall thickness of $15 \mathrm{~mm}$ as measured using SEM and AEM (Figure 1a). The layer is nearly identical to those previously described by Abrajano and Biwer $[5,13]$. The outermost portions consist of birnessite (Mn-hydroxide, characterized by 6-8 $\AA$ basal spacings) and $\mathrm{Mg}$-rich smectite clay (characterized by $15 \AA$ basal spacings, saponite). The poorly crystalline saponite forms in crystals that are perpendicular to the original glass surface and the birnessite forms on the outermost portions of this phase. The saponite sits on a noncrystalline Fe stain that is thought to be a vestige of the original glass surface. Beneath the $\mathrm{Fe}$ sublayer is a poorly crystalline Fe-rich smectite and within this sublayer is a band of $\mathrm{Ni}$-rich serpentine crystal laths. Between these layers and the unreacted glass lies a layer depleted in $\mathrm{Na}$ and presumably, $\mathrm{Li}$ and $\mathrm{B}$ and a uniform continuous interface. 

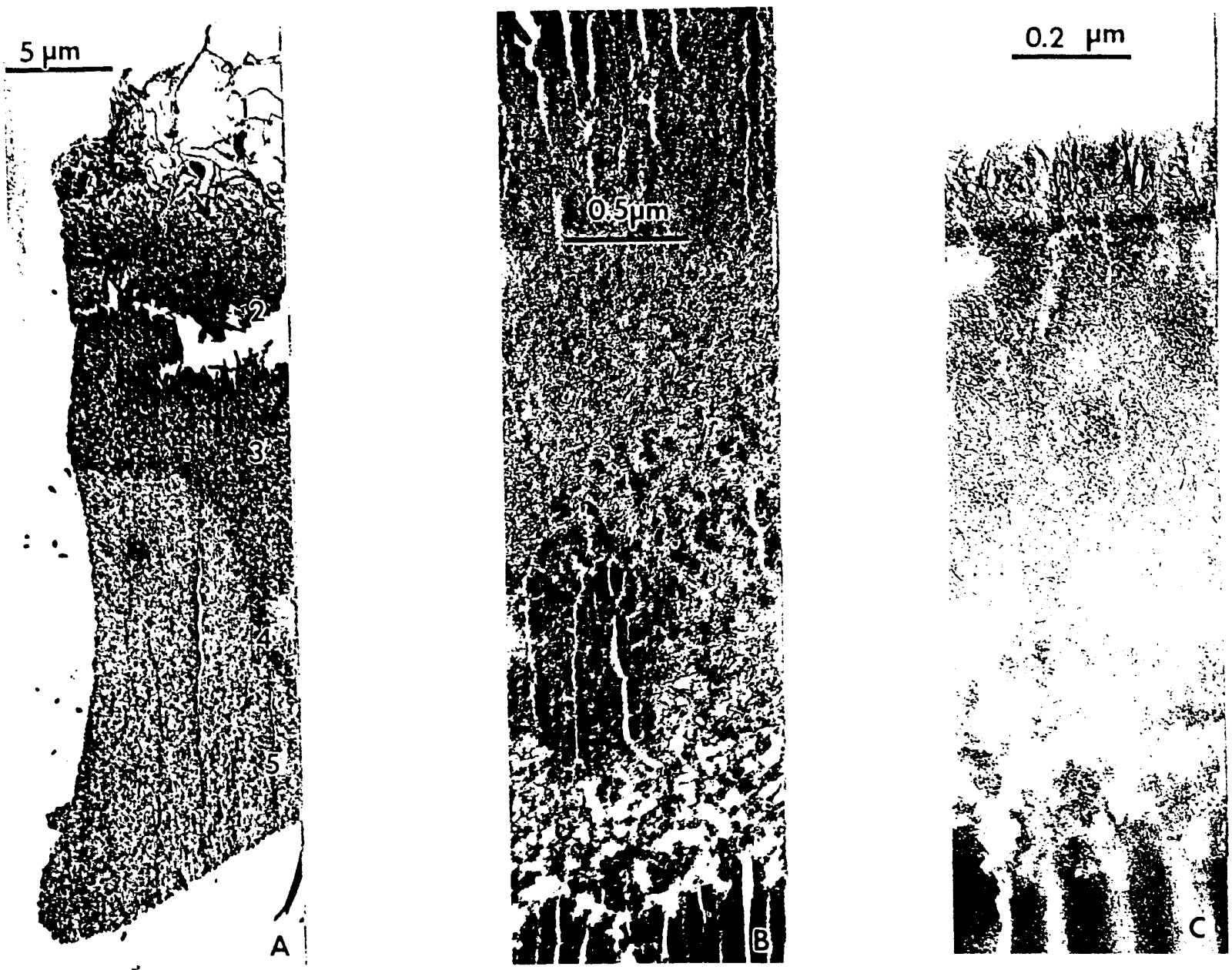

Figure 1. AEM photographs of the alteration layers formed on samples reacted for SVT $=1000 \mathrm{~d} / \mathrm{m}$ : a) sample $A\left(10 \mathrm{~m}^{-1}, 100\right.$ days $), B\left(50 \mathrm{~m}^{-1}\right.$, 20 days) and $c) C\left(100 \mathrm{~m}^{-1}, 10\right.$ days). The alteration assemblage is made up of a number of phases, including a precipitated clay interspersed with birnessite, the outermost layer on sample $A$ only, an Fe-rich band (Layer 2), an Fe-rich smectite layer (nontronite)(Layer 3), an intermixed layer of smectite and serpentine (Layer 4) and a dealkalized gel-like phase containing clay precursors (Layer 5). Note that sample $A$, with a longer reaction time and smaller SAN ratio, has the thickest alteration layer. While the entire alteration assemblages on $B$ and $C$ closely resemble each other, they are significantly different from that found on $A$.

\section{Samples B and C}

The alteration layer formed on samples $B$ and $C$ consists of a four sublayers with overall thicknesses of 3 and $1 \mu \mathrm{m}$, respectively, as measured using SEM and $A E M$ (Figures $1 b$ and $1 c$ ). The outermost clay layer on samples $B$ and $C$ is similar in appearance, texture and composition to the analogous layer on sample $A$. Beneath this clay is an Fe-rich stain, followed by a poorly crystalline Fe-rich smectite clay. Between the Fe-rich clay and the bulk glass is a region of altered glass with that appear to be a mixture of an amorpho:Is gel-like phase and holes in the structure. 


\section{Samples D and E}

The alteration layer formed on sample $D$ consists of two layers with an overall thickness of $0.75 \mu \mathrm{m}$ as measured using SEM and AEM (Figure 2a). The outermost portion of the alteration layer is a perpendicularly oriented saponite layer and the inner portion is poorly crystalline and depleted in sodium, similar in composition and appearance to analogous sublayers found on samples $B$ and $C$. $A$ poorly developed and difficult to detect Fe-rich stain also appears to have formed between the two sublayers. The layer formed on sample $E$ (Figure $2 b$ ) is similar in appearance to that found on sample $D$, except the formation of the Fe-rich stain between the two sublayers is much more prominent. The overall thickness of this alteration layer is $0.25 \mu \mathrm{m}$. As on samples $B$ and $C$, the region nearest the bulk glass is made up of an amorphous gel-like phase with 10 to $50 \mathrm{~nm}$ holes in the structure.
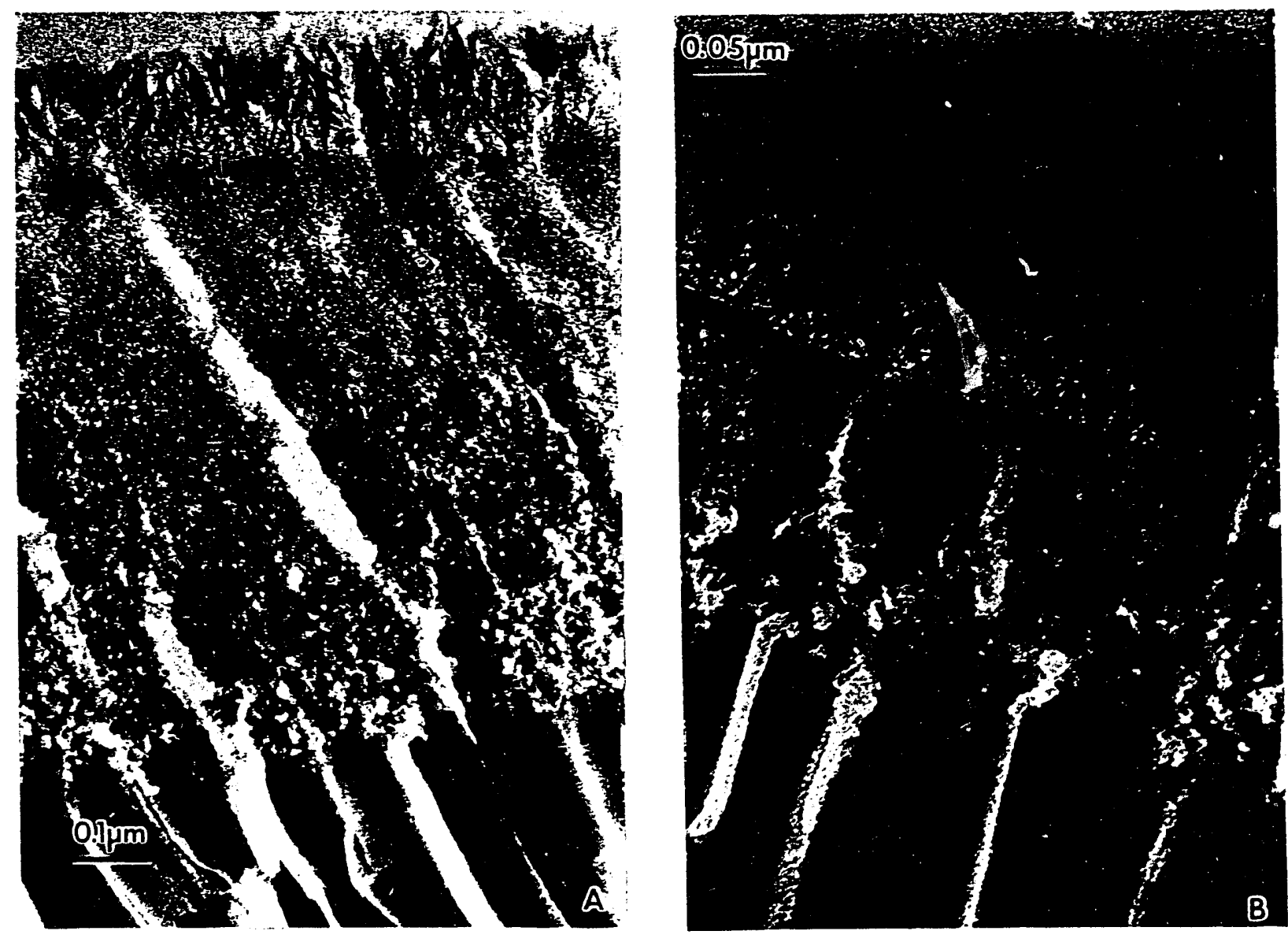

Figure 2. AEM photographs of the alteration layers formed on samples reacted for SVT $=2500 \mathrm{~d} / \mathrm{m}$ : a) sample $D\left(1000 \mathrm{~m}^{-1}, 2.50\right.$ days $)$ and b) $E$ (2000 $\mathrm{m}^{-1}, 1.25$ days). The alteration assemblages on each sample are similar with an outermost precipitated smectite clay layer, with crystals oriented perpendicular to the glass surface, an Fe-rich stain and a dealkalized gel-like phase containing clay precursors. Analogous phases were also found on samples $A, B$, and $C$, although the entire alteration assemblages differ significantly. 
Coupling the results of the solution analyses with the detailed surface characterizations allows an assessment of the overall effect of varying SAV at equivalent values of SVT. For the samples reacted at SVT $=1000 \mathrm{~d} / \mathrm{m}$, the formation of birnessite on sample A correlates with a depletion in the solution $\mathrm{Mn}$ concentration, relative to samples $B$ and $C$. The relatively mature development of the birnessite bearing $\mathrm{Mg}$-rich clay phase on sample $\mathrm{A}$ can also be correlated with the relatively low solution concentrations of $\mathrm{Mg}, \mathrm{Al}$, and $\mathrm{Fe}$, all major clay components. Solution chemistry is less effective in disclosing the nature of the transformed components of the alteration layer (i.e., beneath the Fe-rich stain; [5]). For example, in sample A nickel is concentrating within serpentine laths, a feature not observed in samples B or C, yet the solution concentrations are nearly identical and give no indication of this segregation. The relatively long reaction time for sample A, 100 days, most likely was sufficient for birnessite and Ni-rich serpentine (brindleyite?) precipitation, whereas the reaction times for $\mathrm{B}$ and $\mathrm{C}$ (20 and 10 days, respectively) were not.

The solution concentrations obtained from samples reacted at $2500 \mathrm{~d} / \mathrm{m}$ are greater and the layer thicknesses smaller than those obtained at $1000 \mathrm{~d} / \mathrm{m}$, as would be predicted by the SVT approach [18]. The solution concentrations from samples $D$ and $E$, reacted at $2500 \mathrm{~d} / \mathrm{m}$, show that at longer reaction times the concentrations are relatively lower, except for $\mathrm{Al}$ and $\mathrm{Ni}$, a trend different from the samples reacted at $1000 \mathrm{~d} / \mathrm{m}$ and different from previous reports of SVT scaling [18]. The solution trends from samples $D$ and $E$ probably results from the relatively short reaction times (2.50 and 1.25 days, respectively) and precipitation on the large, highly energetic powciered surface areas. Under our experimental conditions, reaction times of several days do not allow observable precipitation of phases such as birnessite or Ni-rich serpentine, but the outermost clay layer on sample $D$ is significantly thicker than the analogous layer on sample $E$, suggesting that the growth of this phase may be time controlled (i.e., precipitation kinetics controlled), rather than solution concentration related.

The poorly crystalline alkali-depleted sub-layers located between the unreacted glass and the Fe-rich stain (samples $B, C, D$, and E) may be precursors of primitive clay structures that have been described for natural and nuclear waste glass [19]. Primitive clay structures have been described as curved and/or spherical structures between 50 and $1000 \AA$ in diameter and are thought to be precursors to crystalline clay phases during hydration of feldspar minerals [20] and volcanic and nuclear waste glasses [19]. Greater crystallinity was previously reported for nuclear waste forms [19] and it is unclear whether the phases observed on samples $B$ and $C$ would have eventually formed primitive clays. The holes in the deepest layers are likely pockets of solution and are an indication that complete hydrolysis of the glass occurs at the layer/glass interface. In sample A the inner layer was alkali depleted, but had not undergone restructuring and complete hydrolysis.

The results of this study suggest that caution must be exercised in SVT scaling with glasses and experimental conditions that produce significant amounts of secondary phases. Equivalent SVT conditions may result in similar solution concentrations for hydrothermal leach tests, but the nature of the secondary phases that form indicate that different reaction paths are followed which must be accounted for when using laboratory test data to evaluate long-term glass performance. 
The results of this study indicate that identical SVT, but different SA/V ratios can result in the formation of significantly different alteration layers, even though solution concentration data are similar. Precipitation kinetics are probably responsible for the formation of phases such as birnessite and brindleyite in samples reacted for relatively long periods of time and the solution concentration data can be correlated with the appearance of such phases. Solution data needs to be considered in conjunction with alteration phase identification in order to obtain a detailed construction of the reaction mechanism.

\section{ACKNOWLEDGMENTS}

Work supported by the U.S. Department of Energy, Office of Environmental Restoration and Waste Management, under Contract W-31-109-ENG-38.

\section{REFERENCES}

1. BUCKWALTER C. Q., PEDERSON L. R. and MCVAY G. L. (1982) The effects of surface area to solution volume ratio and surface roughness on glass leaching. J. Non-Cryst. Solids 49, 397-412.

2. CHANDLER, G. T., WICKS G. G. and WALLACE R. M. (1986) Effects of SAN and saturation on the chemical durability of SRP waste glass. Adv. Ceram. 20, 455.

3. ETHRIDGE E. C., CLARK D. E. and HENCH L. L. (1979) Effects of surface area to solution volume ratio on glass corrosion. Phys. and Chem. of Glass. 20(2), 35-40.

4. PEDERSON L. R., BUCKWALTER C. Q., McVAY G. L. and RIDDLE B. L. (1983) Glass surface area to solution volume ratio and its implications to accelerated leach testing. in Sci. Bas. for Nucl. Was. Mamt. vol VI, ed. Brookins, Mat. Res. Soc. Symp. Proc. vol. $15, \quad 47-54$.

5. ABRAJANO, T. A., BATES, J.K., WOODLAND, A. B., and BRADLEY J.P. (1990) Secondary phase formation during nuclear waste-glass dissolution. Clay and Clay Minerals $38(5), \quad 537-548$.

6. PETIT J.-C., DELLA MEA G., DRAN J. -C., MAGONTHIER M. -C., MANDO P. A. and PACCAGNELLA A. (1990) Hydrated-layer formation during dissolution of complex silicate glasses and minerals. Geochim. Cosmochim. Acta, 54, 1941-1955.

7. DRAN J. -C., DELLA MEA G., PACCAGNELLA A., PETIT J. C. and TROTIGNON L. (1988) The aqueous dissolution of alkali silicate glasses: reappraisal of mechanisms by $\mathrm{H}$ and $\mathrm{Na}$ depth profiling with high energy ion beams. Phys. and Chem. of Glass. 29, 249255.

8. BOURCIER W. L. (1991) Overview of chemical modeling of nuclear waste glass dissolution. in Sci. Bas, for Nucl. Was. Mgmt, vol VI, eds. Abrajano and Johnson, Mat. Res. Soc. Symp. Proc. vol. 212, 3-18.

9. GRAMBOW B. and STRACHAN D. M. (1991) A comparison of the performance of nuclear waste glasses by modeling. in Sci. Bas. for Nucl. Was. Mgmt. vol Vl, eds. Apted and Westerman, Mat. Res. Soc. Symp. Proc. vol. 112, 713-724.

10. VERNAZ E., ADVOCAT T. and DUSSOSSOY J. L. (1990) Effects of the SAVV ratio on the long-term corrosion kinetics of R7-T7 glass. in Ceramic Transactions, vol. 9 Nuclear waste management III, ed. G. Mellinger, The Amer. Ceram. Soc., Westerville, Ohio, pp. $175-185$.

11. KAMIZONO H., CLARK D. E and LODDING A. R. (1989) Accelerated leach tests of SRL165 high-level waste glass in deionized water. J. Nucl Sci. and Tech. 26, 441-448.

12. CHANDLER G. T., WICKS G. G., and WALLACE R. M. (1986) Effects of SAV and saturation on the chemical durability of SRP waste glass. Savannah River Laboratory report DP-MS-86-56, $14 \mathrm{p}$. 
13. BIWER B. M., BATES J.K., ABRAJANO T. A. and BRADLEY J. P. (1990) Comparison of the layer structure of vapor phase and leached SRL glass by use of AEM. in Sci. Bas, for Nucl. Was. Mamt. vol XIII, eds. Oversby and Brown, Mat. Res. Soc. Symp. Proc. vol. 176, 255-263.

14. BRADLEY J. P. (1988) Analysis of chondritic interplanetary dust thin sections. Geochimica et Cosmochim. Acta. 52, 889-900.

15. CLIFF G. and LORIMER G. W. (1975) The quantitative analysis of thin-sections. J. Microsc. 103, 203-207.

16. SHERIDAN P. (1989) Determination of experimental and theoretical KAS factors for a $200 \mathrm{keV}$ analytical electron microscope. J. Electron Microsc. Tech. 11, 41-61.

17. BOHOR B. F. and HUGHES R. E. (1971) Scanning Electron Microscopy of Clays and Clay Minerals. Clays and Clay Minerals 19, 49-54.

18. PEDERSON L. R., BUCKWALTER C. Q., MCVAY G. L. (1983) The effects of surface area to solution volume on waste glass leaching. Nucl. Technol. 62, 151.

19. TAZAKI K., FYFE W. S. and VAN DER GAAST S. J. (1989) Growth of Clay Minerals in Natural and Synthetic Glasses. Clays and Clay Minerals 37(4), 348-354.

20. EGGLETON, R. A. (1987) Noncrystalline Fe-Si-Al-oxyhydroxides. Clays and Clay Minerals 35, 29-37. 

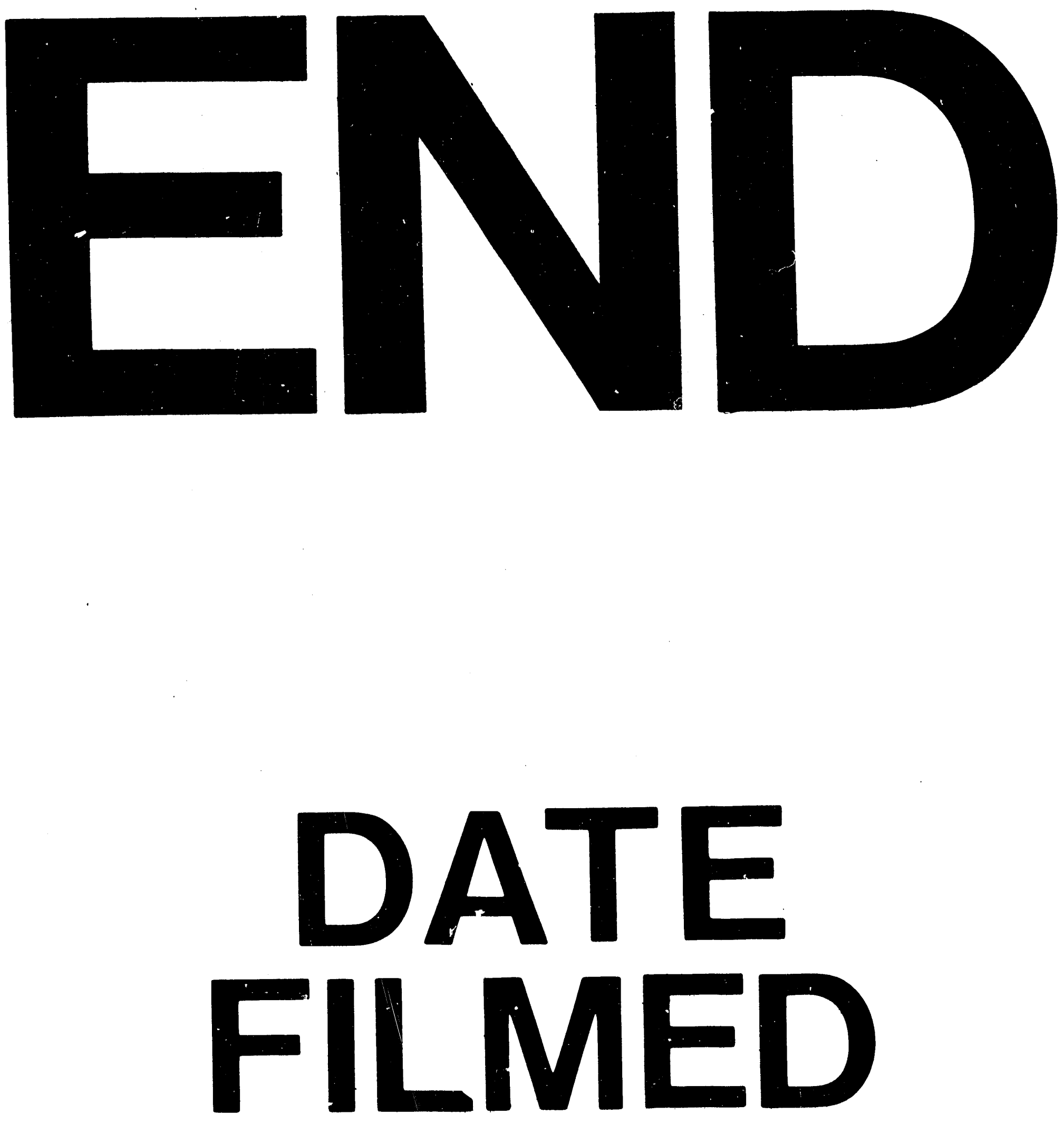

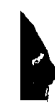

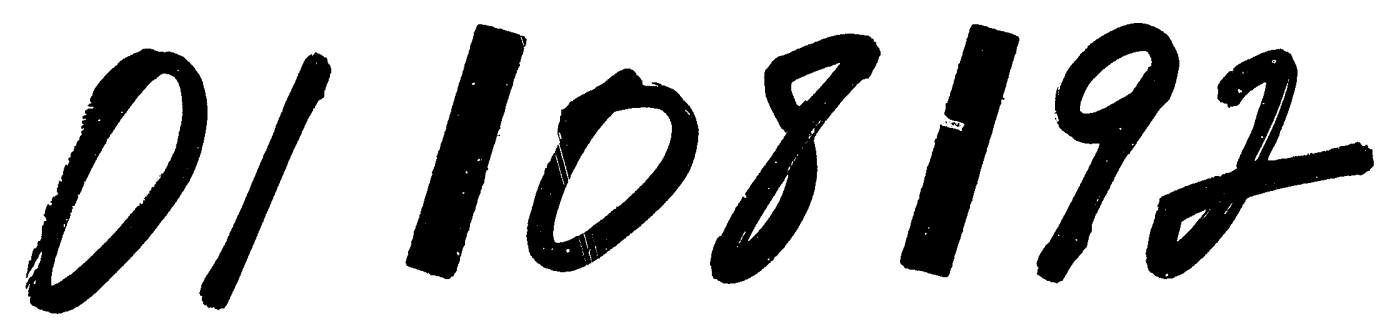


